\title{
Monoclonal antibody against H1N1 influenza virus hemagglutinin cross reacts with hnRNPA1 and hnRNPA2/B1
}

\author{
CHUNYAN GUO ${ }^{1}$, LIJUN SUN ${ }^{1}$, SHUANGPING HAO ${ }^{2}$, XIAOYAN HUANG $^{1}$, HANYU HU $^{3}$, \\ DAOYAN LIANG ${ }^{1}$, QING FENG ${ }^{1}$, YAN LI $^{1}$, YANGMENG FENG ${ }^{1}, \mathrm{XIN} \mathrm{XIE}^{4}$ and JUN HU ${ }^{1}$ \\ ${ }^{1}$ Central Laboratory of Shaanxi Provincial People's Hospital, The Third Affiliated Hospital of Medical School, \\ Xi'an Jiaotong University, Shaanxi Province Research Centre of Cell Immunological Engineering and Technology, \\ Key Laboratory of Microbial Infections and Autoimmune Diseases, Xi'an, Shaanxi 710068; \\ ${ }^{2}$ Guangshui Traditional Chinese Medicine Hospital of Hubei Province, Guangshui, Hubei 432700, P.R. China; \\ ${ }^{3}$ School of Public Health and Tropical Medicine, Tulane University, New Orleans, LA 70112, USA; \\ ${ }^{4}$ Key Laboratory of Resource Biology and Biotechnology in Western China, Ministry of Education, \\ College of Life Sciences, Northwest University, Xi'an, Shaanxi 710069, P.R. China
}

Received December 10, 2019; Accepted July 30, 2020

DOI: $10.3892 / \mathrm{mmr} .2020 .11494$

\begin{abstract}
Following influenza A vaccination, certain individuals exhibit adverse reactions in the nervous system, which causes a problem with the safety of the influenza A vaccine. However, to the best of our knowledge, the underlying mechanism of this is unknown. The present study revealed that a monoclonal antibody (H1-84mAb) against the H1N1 influenza virus hemagglutinin (HA) protein cross-reacted with an antigen from brain tissue. Total brain tissue protein was immunoprecipitated with this cross-reactive antibody, and mass spectrometry revealed that the bound antigens were heterogeneous nuclear ribonucleoprotein (hnRNP) A1 and hnRNPA2/B1. Subsequently, the two proteins were expressed in bacteria and it was demonstrated that $\mathrm{H} 1-84 \mathrm{mAb}$ bound to hnRNPA1 and hnRNPA2/B1. These two proteins were expressed in three segments and the cross-reactivity of H1-84mAb with the glycine (Gly)-rich domains of hnRNPA1 (195aa-320aa) and hnRNPA2/B1 (202aa-349aa) was determined using ELISA blocking experiments. It was concluded
\end{abstract}

Correspondence to: Professor Xin Xie, Key Laboratory of Resource Biology and Biotechnology in Western China, Ministry of Education, College of Life Sciences, Northwest University, 229 Taibai North Road, Xi'an, Shaanxi 710069, P.R. China

E-mail: xiexin@nwu.edu.cn

Professor Jun Hu, Central Laboratory of Shaanxi Provincial People's Hospital, The Third Affiliated Hospital of Medical School, Xi'an Jiaotong University, Shaanxi Province Research Centre of Cell Immunological Engineering and Technology, Key Laboratory of Microbial Infections and Autoimmune Diseases, 256 Youyi West Road, Xi'an, Shaanxi 710068, P.R. China

E-mail: 78364282@qq.com

Key words: influenza virus, cross-reactivity, nervous system disease, glycine-rich domain that the Gly-rich domains of these two proteins are heterophilic antigens that cross-react with influenza virus HA. The association between the heterophilic antigen Gly-rich domains and the safety of influenza A vaccines remains to be investigated.

\section{Introduction}

Influenza A infection may cause central nervous system complications, including multiple sclerosis, febrile seizures, encephalopathy and Reye's syndrome, as well as other neurological abnormalities, high mortality, poor prognosis and sequelae in the majority of survivors (1-5). Vaccination is the most effective method of preventing and controlling influenza. However, due to certain factors, including the immunological characteristics of the influenza vaccine itself, a small number of influenza vaccination subjects may develop diseases, including Guillain-Barré syndrome and narcolepsy, while obtaining immunoprotection. At present, to the best of our knowledge, the causes of these serious adverse reactions remain unclear $(6,7)$.

In our previous study, 84 monoclonal antibodies (mAbs) against hemagglutinin (HA) were prepared. When identifying their characteristics, it was revealed that the $\mathrm{H} 1-84 \mathrm{mAb}$ not only binds to the HA antigen, but also cross-reacts with human brain tissue, suggesting that H1N1 influenza virus HA and human brain tissue have a heterophilic antigen (8). Heterophilic antigens are a class of common antigens that are unrelated between species, and exist in humans, animals and microorganisms (9). When studying microbial infection immunity, it has been revealed that $E$. coli $\mathrm{O} 14$ lipopolysaccharide and human colon mucosa possess heterophilic antigens, leading to the occurrence of ulcerative colitis (10). Antibodies against the enterovirus Coxsackie VP1 protein may cross-react with mitochondrial proteins of $\beta$-islet cells, and this may be associated with infection-induced diabetes (11).

The presence of heterophilic antigens between influenza HA and human brain tissue may be an important factor affecting the safety of the influenza A vaccine. Therefore, 
it is important to find and identify heterophilic antigens recognised by $\mathrm{H} 1-84 \mathrm{mAb}$. It has been previously identified that $\mathrm{H} 1-84 \mathrm{mAb}$ recognises a nine-peptide linear epitope of influenza HA (12). The present study used H1-84mAb as a research tool to confirm its cross-reactivity with heterophilic antigens from brain tissue and to provide experimental data for subsequent studies investigating the pathogenic mechanism involving these antigens.

\section{Materials and methods}

Experimental materials. A total of 5 Male Sprague Dawley (SD) rats (weight, 250-300 g) were purchased from the Experimental Animal Centre of the Fourth Military Medical University (Xi'an, China) in order to prepare paraffin sections and total protein extracts of rat brain tissues. The 6-8-week SD rats received humane care and were raised in the same clean environment, with ambient temperature at $26^{\circ} \mathrm{C}$, humidity of $50 \pm 5 \%$, and a 12 -h light/dark cycle. In addition, the standard food and water available ad libitum to the animals was sterilized. Following the experiments, the animals were anesthetized with ether, and clinical manifestations included loss of consciousness, loss of systemic pain, inhibition of reflexes, and skeletal muscle relaxation. The animals were euthanized by cervical dislocation. Cell culture supernatant of the H1-84mAb against influenza virus hemagglutinin was maintained in our laboratory (titre, 1:1,000; https://doi.org/10.1007/s12250-019-00100-9). A horseradish peroxidase-labelled goat anti-mouse secondary antibody (cat. no. B141027) and a tissue immunohistochemical staining kit (cat. no. QN2755) were purchased from OriGene Technologies, Inc. Bovine serum (cat. no. 16000-044) for cell cultures was purchased from Hangzhou Sijiqing Biological Engineering Materials Co., Ltd. RIPA lysis buffer (cat. no. P0013C) and BeyoECL Plus (cat. no. P0018S) were purchased from Beyotime Institute of Biotechnology. The SP2/0 hybridoma cells were purchased from Hangzhou Lianke Meixun Biomedical Technology Co., Ltd. (cat. no. YB-ATCC-2224). BL21(DE3)pLysS competent cells, $>106 \mathrm{cfu} / \mu \mathrm{g}$, were purchased from Promega Corporation (cat. no. L1191). Protein A/G PLUS agarose (cat. no. GS4780) was purchased from Santa Cruz Biotechnology, Inc. The total RNA extraction kit (cat. no. DP433), cDNA first-strand synthesis kit (cat. no. KR104) and bicinchoninic acid (BCA) protein assay kit (cat.no. P0012S) were purchased from Tiangen Biotech Co., Ltd. PCR polymerase (cat. no. C10966-018), the pMD19-T vector (cat. no. 6013) and DM5000 DNA Marker (cat. no. 116899) were purchased from Takara Biotechnology Co., Ltd., and a prokaryotic expression vector was kept at our laboratory. Primer synthesis and sequencing were performed by Beijing Liuhe Huada Gene Technology Co., Ltd.

Preparation and identification of $m A b s$. mAbs against the $\mathrm{H} 1 \mathrm{~N} 1$ influenza virus HA protein, including H1-84mAb, were prepared in our laboratory. The titre of the antibody was determined using the indirect ELISA method, and the reactivity of the antibody with the HA antigen was determined by western blotting (8). It has been previously determined that $\mathrm{H} 1-84 \mathrm{mAb}$ binds to a nine-peptide linear epitope (191-LVLWGIHHP-199) on HA (12).
Immunohistochemistry. In brief, SD rat brain tissues were obtained to generate paraffin sections. Immunohistochemical staining was performed according to the kit instructions. Paraffin sections were dewaxed in xylene, rehydrated with alcohol at gradient concentration, and finally soaked in distilled water. Citrate buffer ( $\mathrm{pH}$ 6.0) was used for antigen retrieval at $60^{\circ} \mathrm{C}$ microwave. Subsequently, $3 \%$ hydrogen peroxide was used to block endogenous peroxidase activity at room temperature for $20 \mathrm{~min}$, followed by blocking in 3\% sheep serum at $37^{\circ} \mathrm{C}$ for $30 \mathrm{~min}$. The sections were incubated with $\mathrm{H} 1-84 \mathrm{mAb}$ (dilution, 1:50) at $4^{\circ} \mathrm{C}$ overnight. Subsequently, the sections were rewarmed to room temperature for $60 \mathrm{~min}$, followed by three washes with phosphate-buffered saline (PBS). The horseradish peroxidase-labelled goat anti-mouse secondary antibody (dilution, 1:500) was added and incubated at $37^{\circ} \mathrm{C}$ for $40 \mathrm{~min}$, followed by three washes with PBS. Colour development was performed with diaminobenzidine and haematoxylin counterstaining at room temperature for $10 \mathrm{~min}$. A conventional dehydrated transparent neutral gum mounting medium was used. Negative control was established.

Immunoprecipitation and mass spectrometry. As previously described (13), total protein was extracted from rat brain tissues using RIPA lysis buffer, and lysed on ice or at $4^{\circ} \mathrm{C}$ for $30 \mathrm{~min}$. The supernatant was collected following centrifugation at $12,000 \mathrm{x} \mathrm{g}$ for $30 \mathrm{~min}$ at $4^{\circ} \mathrm{C}$. The protein content was determined using a BCA protein assay kit. A total of $500 \mu \mathrm{g}$ of the collected protein was transferred to a $1.5-\mathrm{ml}$ microcentrifuge tube, and $2 \mu \mathrm{g} \mathrm{H} 1-84 \mathrm{mAb}$ was added and incubated at $4^{\circ} \mathrm{C}$ for $1 \mathrm{~h}$. Next, $20 \mu \mathrm{l}$ of a resuspended volume of protein A/G PLUS agarose was added. This was incubated overnight at $4^{\circ} \mathrm{C}$ with gentle agitation. Following immunoprecipitation, the samples were centrifuged at $1,500 \mathrm{x}$ g for $5 \mathrm{~min}$ at $4^{\circ} \mathrm{C}$. The protein $\mathrm{A} / \mathrm{G}$ beads were centrifuged to the bottom of the tube, the supernatant was carefully aspirated, the protein $\mathrm{A} / \mathrm{G}$ beads were washed 3-4 times with $1 \mathrm{ml}$ lysis buffer, and finally $15 \mu 12 \mathrm{X}$ SDS loading buffer was added and the samples were boiled for $10 \mathrm{~min}$. Samples were then analysed by SDS-PAGE, western blotting and mass spectrometry.

Western blotting. The sample was mixed with SDS electrophoresis sample buffer and the protein was transferred onto a nitrocellulose membrane following SDS-PAGE on a $12 \%$ separation gel. Then the protein gel was transferred to the NC film and blocked overnight with $5 \%$ skimmed milk at $4{ }^{\circ} \mathrm{C}$. $\mathrm{H} 1-84 \mathrm{mAb}$ was used as the primary antibody (dilution, 1:100). A goat anti-mouse enzyme-labelled secondary antibody, as mentioned above, (dilution, 1:2,500) was used. Enhanced chemiluminescence (ECL) was used to develop the colour.

Cloning of heterogeneous nuclear ribonucleoprotein (hnRNP) $A 1$ and $h n R N P A 2 / B 1$. As previously described (14), total RNA was extracted from brain tissue total protein and then reverse transcribed into cDNA. Subsequently, PCR was used to amplify hnRNPA1 and hnRNPA $2 / \mu 1$. The $6 \mu 1$ purified PCR product was subcloned into the $2 \mu 1$ pGEM $^{\circledR}$-T vector (concentration ratio $3: 1$ ). The correctly sequenced plasmid was converted into the pET-28a-SUMO vector (SUMO tag size, $15 \mathrm{kDa}$ ) and then was transformed into BL21(DE3) pLysS competent cells by thermal shock for $90 \mathrm{sec}$ at $42^{\circ} \mathrm{C}$. 

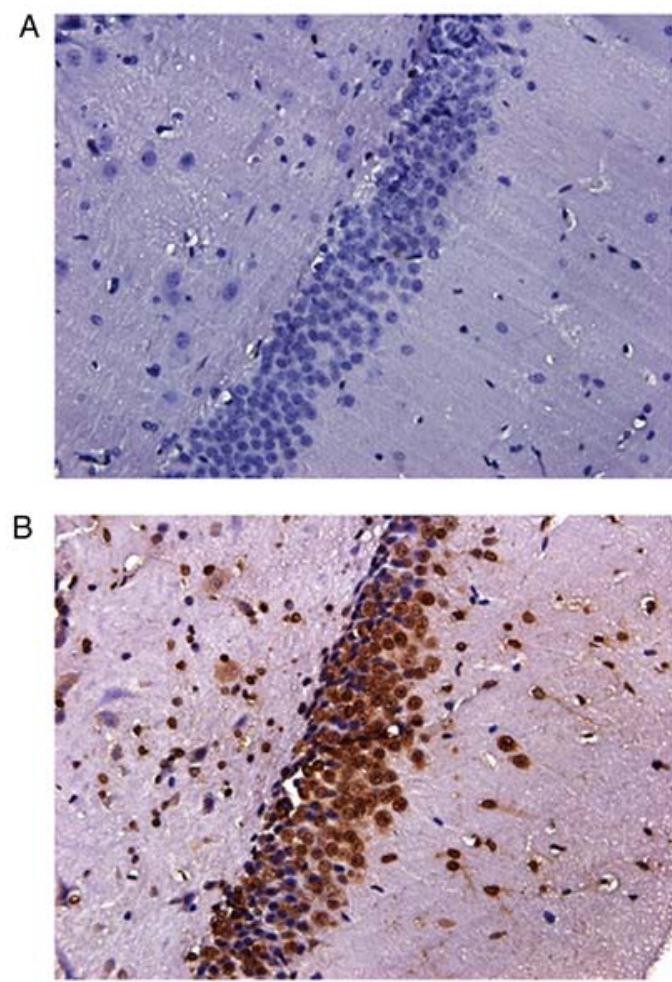

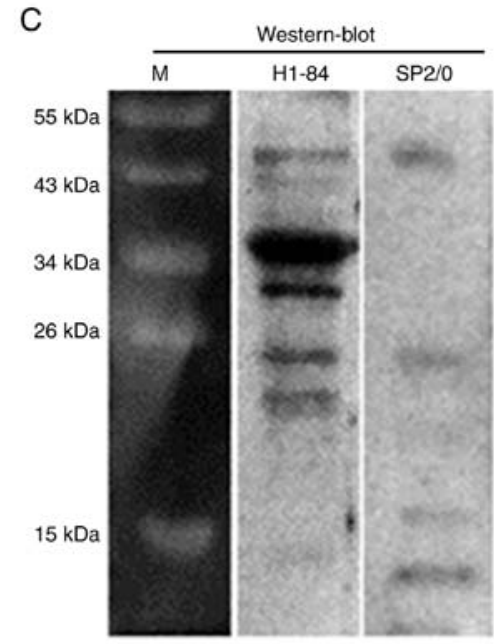

Figure 1. Identification of H1-84mAb combined with rat brain tissue. (A) SP2/0 as a negative control did not respond to brain tissue cells. Magnification, $\mathrm{x} 400$. (B) $\mathrm{H} 1-84 \mathrm{mAb}$ was bound to rat brain tissue and parts of the cerebral cell nucleus were stained brownish yellow. Magnification, $\mathrm{x} 400$. (C) $\mathrm{H} 1-84 \mathrm{mAb}$ reacted with the protein components of brain tissue, and the molecular weight was $\sim 35 \mathrm{kDa}$ (lane 2); SP2/0 was used as negative control (lane 3).

Recombinant hnRNPA1 and hnRNPA2/B1 were expressed by adding isopropyl $\beta$-d-1-thiogalactopyranoside (IPTG; $0.5 \mathrm{mM}$ ) to an $E$. coli strain, purified using Ni-NTA and verified on Coomassie-stained gels.

Segmental expression and identification of hnRNPAl and $A 2 / B 1$. The antigenicity of hnRNPA1 and hnRNPA2/B1 were analyzed theoretically. Using hnRNPA1 and hnRNPA2/B1 as templates, PCR was used to amplify truncated hnRNPA1 and hnRNPA2/B1, using the aforementioned steps. Truncated hnRNPA1 and hnRNPA2/B1 were expressed by adding IPTG $(0.5 \mathrm{mM})$ to an $E$. coli strain, purified using Ni-NTA and verified on Coomassie-stained gels. The expression product was identified by SDS-PAGE and western blotting.

Statistical analysis. The results were analyzed using SPSS 19.0 statistical software (IBM Corp., Armonk, NY, USA). Data are expressed as the mean \pm SEM. One-way analysis of variance, followed by Tukey's post hoc test, was used to determine the significance of differences in multiple comparisons. $\mathrm{P}<0.05$ was considered to indicate a statistically significant difference.

\section{Results}

Cross-reactivity of influenza virus $H A$ mA $b$ with rat brain tissue. In our previous study, $84 \mathrm{mAbs}$ against influenza virus HA were obtained and screened using a human tissue microarray. H1-84mAb cross-reacted with human brain tissue, and western blotting revealed that $\mathrm{H} 1-84 \mathrm{mAb}$ bound to the HA antigen (8).

Due to the limitations of medical ethics, the present study used rat brain tissues instead of human brain tissues for subsequent experiments. To further confirm the cross-reactivity of $\mathrm{H} 1-84 \mathrm{mAb}$, immunohistochemical staining of paraffin sections of rat brain tissues was performed. The results revealed that the control antibody (cell culture supernatant of the SP2/0 hybridoma) was negative (Fig. 1A). Additionally, H1-84mAb reacted with the rat brain (Fig. 1B). Furthermore, western blotting demonstrated that $\mathrm{H} 1-84 \mathrm{mAb}$ reacted with the protein components of brain tissue. The molecular weight of the reactive protein was $\sim 35 \mathrm{kDa}$ (Fig. 1C).

Immunoprecipitation and mass spectrometry. $\mathrm{H} 1-84 \mathrm{mAb}$ bound to the protein in rat brain tissue in immunoprecipitation experiments. The cell culture supernatant of the SP2/0 hybridoma served as a negative control. Western blotting revealed that the molecular weight of the target antigen reacting with $\mathrm{H} 1-84 \mathrm{mAb}$ was $\sim 35 \mathrm{kDa}$ (Fig. 2A). Specific reaction bands were excised from the SDS-PAGE gel and analysed by mass spectrometry.

Verification of cross reactivity. Immunoprecipitation combined with mass spectrometry indicated that $\mathrm{H} 1-84 \mathrm{mAb}$ bound to hnRNPA1 andhnRNPA2/B1 frombrain tissues. The two proteins were expressed separately using an $E$. coli expression system (Fig. 2B). Subsequently, the cross-reactivity of the expressed proteins with $\mathrm{H} 1-84 \mathrm{mAb}$ was demonstrated by western blotting. The results revealed that $\mathrm{H} 1-84 \mathrm{mAb}$ cross-reacted with the two purified recombinant proteins (Fig. 2C).

Fine localisation of H1-84mAb binding to brain tissue proteins. The functional regions of the hnRNPA1 and hnRNPA2/B1 proteins were analysed (Figs. 3A and 4A); they were divided into three segments and prokaryotic expression 
A
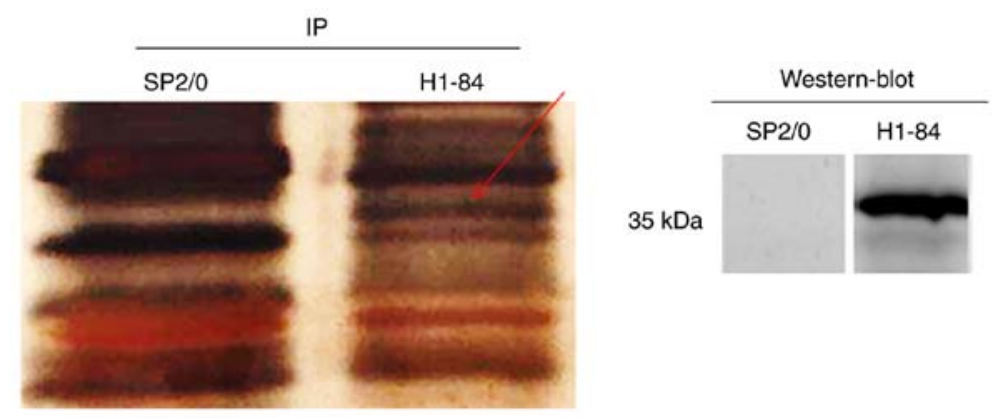

B
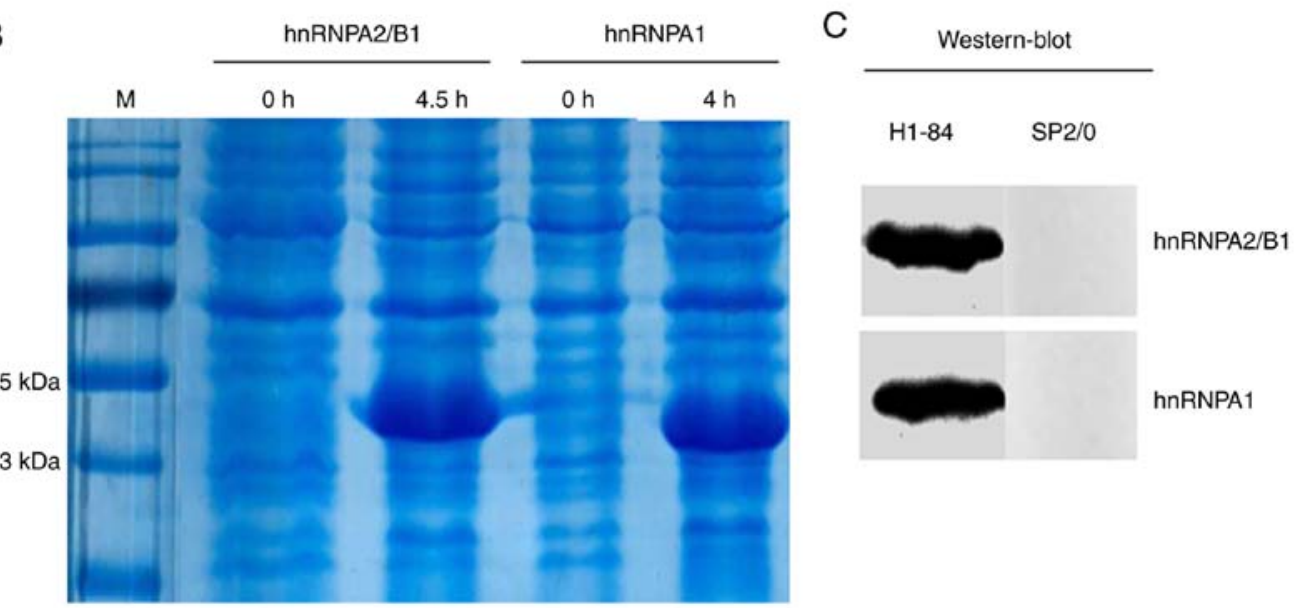

Figure 2. Immunoprecipitation and identification of hnRNPA2/B1 and hnRNPA1 protein expressed in bacteria. (A) Western blot analysis of brain tissue protein following immunoprecipitation. SP2/0 (lane 1) and H1-84 (lane 2) were used as the primary antibodies. The red arrow indicated specific banding, which was performed for mass spectrometry. Lane 3 and lane 4 show that the target antigen, which specifically reacted with $\mathrm{H1}-84 \mathrm{mAb}$, was $\sim 35 \mathrm{kDa}$. (B) Coomassie-stained gels revealed that hnRNPA2/B1 and hnRNPA1 expressed in bacteria were $\sim 50 \mathrm{kDa}$ (SUMO tag size was $15 \mathrm{kDa}$ ). (C) Western blot analysis demonstrated that H1-84mAb bound to the recombinant protein hnRNPA2/B1 and hnRNPA1.

A

Antigenic analysis of hnRNPA1

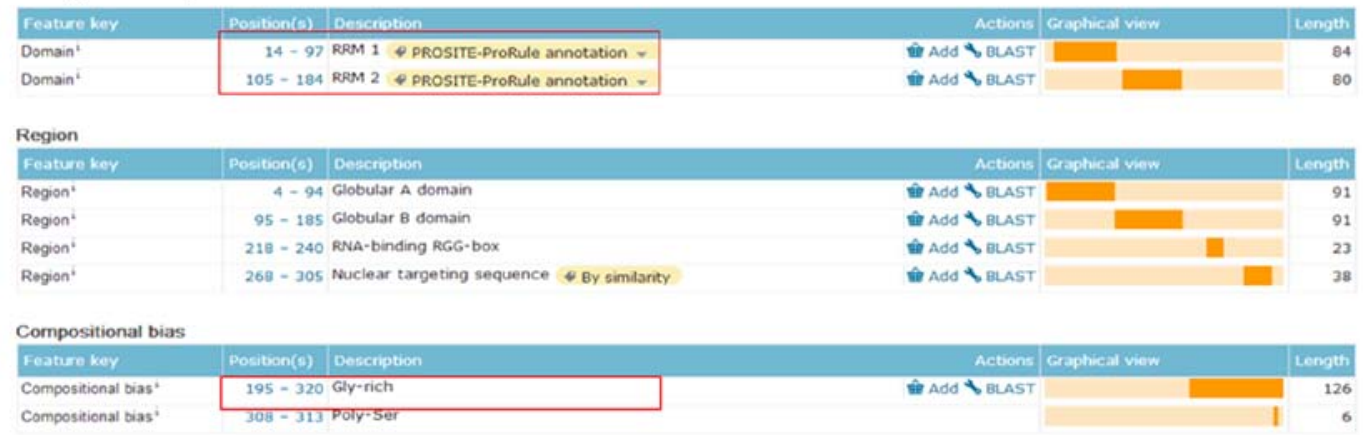

B

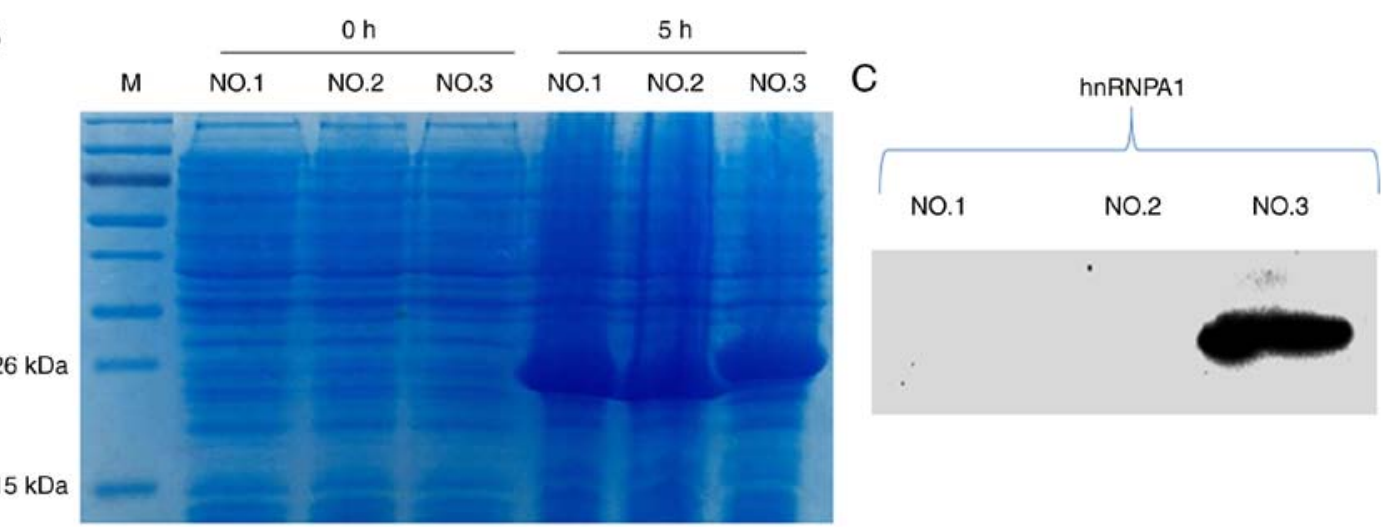

Figure 3. Fine localization of H1-84mAb bound to the hnRNPA1. (A) Antigenic analysis of hnRNPA1. (B) hnRNPA1 was expressed in stages, which were NO.1 (14-97aa), NO.2 (105-184aa), and NO.3 (195-320aa). All three proteins were correctly expressed. (C) Western blot analysis revealed that H1-84mAb bound to the NO.3 of the hnRNPA1. NO.1, stands for RRM1 domain; NO.2, stands for RRM2 domain; NO.3, stands for Gly-rich domain. 
was performed (Figs. 3B and 4B). Subsequently, western blot analysis was used to identify them. The results revealed that the third segments [the glycine (Gly)-rich domain] of these two proteins were the antigens that $\mathrm{H} 1-84$ cross-reacted with in brain tissues (Figs. 3C and 4C). Fig. 3C demonstrated that hnRNPA1-NO.3 (195aa-320aa Gly-rich domain) contained 126 amino acids. Fig. 4C demonstrated that hnRNPA2/B1-NO.3 (202aa-349aa Gly-rich domain) contained 148 amino acids. These two parts were $\mathrm{H} 1-84 \mathrm{mAb}$ that recognized specific antigens on hnRNPA1 and hnRNPA2/B1.

Verification of H1-84mAb combined with brain tissue antigens. The hnRNPA1-NO.3 and hnRNPA2/B1-NO.3 were purified (Fig. 5A) and then these two antigens were used to block the binding of H1-84 to brain tissue proteins, respectively. The same batch of brain tissue proteins was sampled for western blot analyses, and the consistency of the sample volume was monitored with $\beta$-actin. The H1-84mAb was pre-incubated with $0,0.2$ and $0.6 \mu \mathrm{g}$ of the glycine (Gly)-rich domain of these two proteins, respectively, and then reacted with the brain tissue proteins on the $\mathrm{NC}$ membrane, ${ }^{*} \mathrm{P}<0.05 \mathrm{vs} .0 \mu \mathrm{g}$ group. It was verified that these two partial antigens may block $\mathrm{H} 1-84 \mathrm{mAb}$ binding to brain tissue (Fig. 5B).

\section{Discussion}

Influenza A vaccination may induce neurological adverse reactions in a small number of individuals, indicating that there is a problem with the safety of the influenza A vaccine $(3,15)$. At present, the mechanism of this remains unclear, which limits the efficiency of clinical prevention and control, and seriously affects the treatment of patients. In 2015, Ahmed et al (16) reported that the nucleoproteins of influenza A vaccines stimulate the body to produce cross-reactive antibodies against hypothalamic receptor 2 . This antibody blocks the hypothalamic receptors of nerve cells, leading to a sleep-wake regulation disorder, which in turn causes narcolepsy $(17,18)$.

Our previous study demonstrated that influenza virus $\mathrm{H} 1-84 \mathrm{mAb}$ not only bound to the HA antigen, but also reacted with human brain tissue (8). Combined with the concept of heterophilic antigens, this indicated that there was a heterotropic antigen between influenza virus HA and human brain tissue. This is an important factor affecting the safety of the vaccine. Using molecular biology and immunological methods, the present study demonstrated that the influenza virus $\mathrm{H} 1-84 \mathrm{mAb}$ cross-reacted with heterophilic antigens in brain tissues. The heterophilic antigens were the Gly-rich domains of hnRNPA1 (195aa-320aa) and hnRNPA2/B1 (202aa-349aa) by prokaryotic expression. Although the protein expressed in the bacterial system cannot simulate the natural protein in nuclear organisms, the current research field mostly uses prokaryotic expression methods to identify heterophilic antigens. Sun et al (13) used a prokaryotic expression method to report that the anti-influenza virus $\mathrm{H} 1-50 \mathrm{mAb}$ recognizes target antigen inhibin on pancreatic islet cells. Furthermore, an article published in Nature Medicine confirmed that an antibody produced by human $\mathrm{T}$ lymphotropic virus type 1 (HTLV-1) infection reacts with hnRNPA1 to cause myelopathy/tropical paraplegia (HAM/TSP) by prokaryotic expression (14). Therefore, the present study used the prokaryotic expression method to verify heterophilic antigens.
hnRNP is a multifunctional protein family molecule that is mainly localised in the nucleus and may be combined with newly-synthesised heterogeneous nuclear RNA. It regulates a series of important processes, including the splicing of mRNA precursors, as well as mRNA nuclear transport, translation and degradation (19). In studies investigating how viral diseases cause neurological diseases, there have been various reports on spontaneous host antibodies, and a number of studies have focused on the pathogenicity of hnRNP antibodies. Levin et al (20) revealed that autoantibodies to hnRNPA1 may cause neurodegenerative changes. Animal experiments have demonstrated that hnRNPA1 antibodies are associated with multiple sclerosis (21). Sueoka et al (22) detected antibodies in the cerebrospinal fluid of 35 patients with multiple sclerosis and reported that 32 of them had antibodies against the hnRNPB1 protein. The present experiments revealed that the $\mathrm{H} 1-84 \mathrm{mAb}$ of influenza virus HA binds to Gly-rich domains of hnRNPA1 and hnRNPA2/B1. The proteins hnRNPA1 and hnRNPA2/B1 were screened using the IP method and were highly expressed in neurons. The Gly-rich domain of these two proteins may block the binding of $\mathrm{H} 1-84 \mathrm{mAb}$ to brain tissue.

The Gly-rich domain includes the RGG domain and the M9 shuttle domain, which are two important functional regions of hnRNP. Antibodies against these two functional domains may cause nervous system damage (23). Therefore, the specific epitope of H1-84 binding to the Gly-rich domain and the pathogenesis of neurological diseases caused by H1-84mAb binding to the Gly-rich domains of these proteins should be studied.

Although hnRNP is widely distributed in various cells and tissues of different species, H1-84mAb specifically binds to brain tissue. Furthermore, Sun et al (13) reported that anti-influenza virus $\mathrm{H} 1-50 \mathrm{mAb}$ recognises a target antigen on islet cells, which has been revealed to be prohibitin. Prohibitin is an antiproliferative protein that is widely distributed in various cell types in different species, and serves an important regulatory role in cell metabolism, growth, differentiation, senescence and apoptosis (24).

The present study compared the similarity between the HA of influenza virus and the Gly-rich domain of hnRNPA1 and hnRNPA2/B1; and they were found to have no homologous sequences. Sun et al (13) revealed that an influenza virus $\mathrm{mAb}$ (H1-50) cross-reacts with islet cells, but there is no homologous sequence between HA and prohibitin. Previous studies $(14,25)$ revealed that an antibody produced by human $\mathrm{T}$ lymphotropic virus type 1 infection reacts with hnRNPA1 to cause myelopathy/tropical paraplegia. Although there is no homologous sequence between the dominant epitope (KHFRETEV) and hnRNPA1, autoantibodies against hnRNPA1 may still cause neuronal damage. In a mouse model of viral-induced myocarditis, a cross-reaction was found between myocardial myosin and Coxsackie B3 virus neutralizing antibody, but no molecularly mimicked sequence was found (26). Not all cross-reactions can find homologous sequences, as they may be conformational fit.

$\mathrm{H} 1-84 \mathrm{mAb}$ may recognize $\mathrm{HA}$ antigens of human 2009H1N1, seasonal H1N1, H3N2, avian influenza H5N1 and $\mathrm{H} 9 \mathrm{~N} 2$. It was reported that $\mathrm{H} 1-84 \mathrm{mAb}$ can recognize the epitope 191-LVLWGIHHP-199 of human influenza and avian influenza HA (12). Antibodies that recognize this epitope have also been detected in patients' sera following vaccination, and our recent studies have reported that $\mathrm{H} 1-84 \mathrm{mAb}$ may mediate nervous system damage (study under submission). Therefore, 
A

Antigenic analysis of hnRNPA2/B1
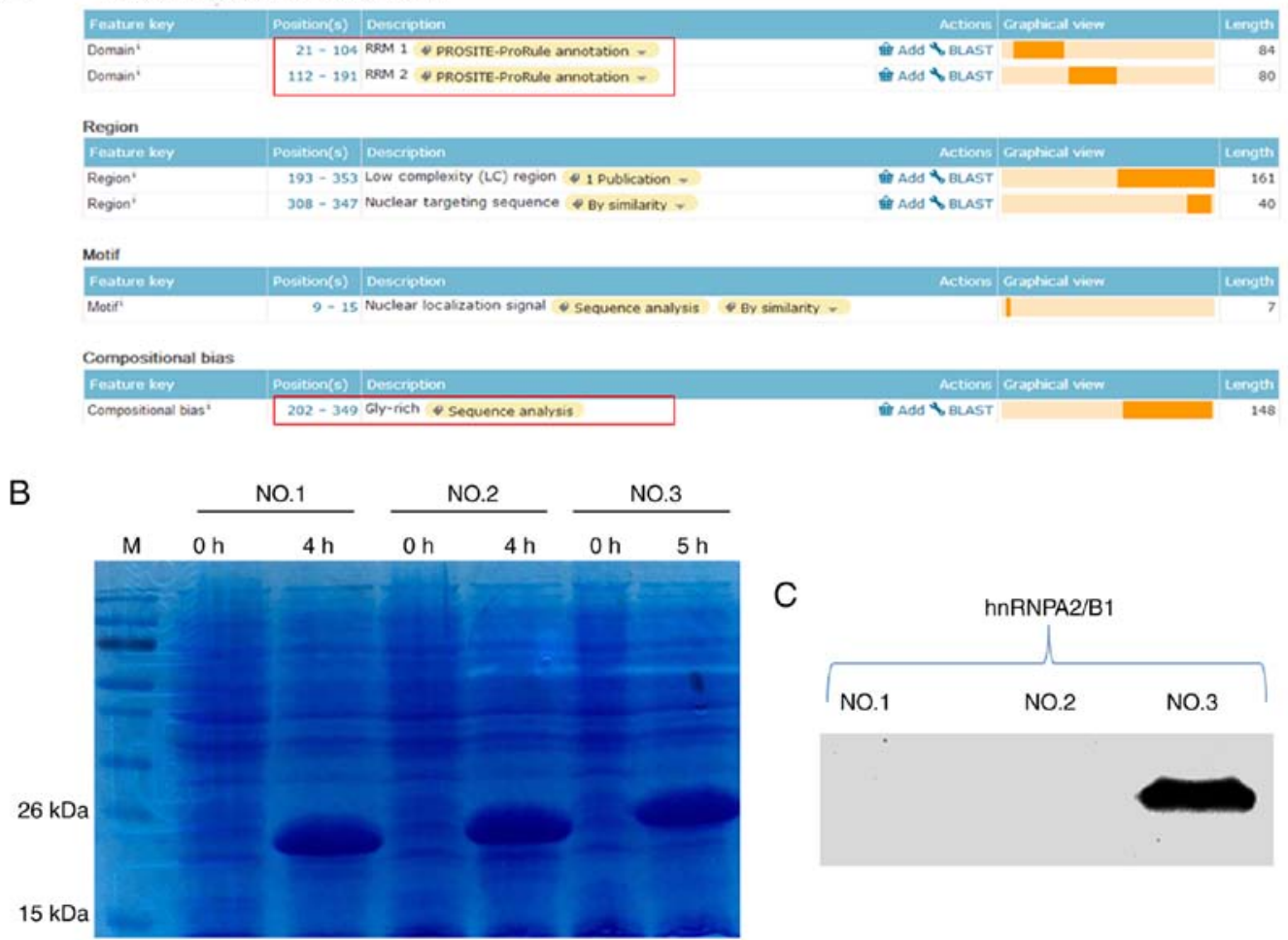

Figure 4. Fine localization of H1-84mAb bound to the hnRNPA2/B1. (A) Antigenic analysis of hnRNPA2/B1. (B) hnRNPA2/B1 was expressed in stages, which were NO.1 (21-111aa), NO.2 (112-191aa) and NO.3 (202-349aa). All three proteins were correctly expressed. (C) Western blot analysis revealed that $\mathrm{H} 1-84 \mathrm{mAb}$ bound to the NO.3 of the hnRNPA2/B1.

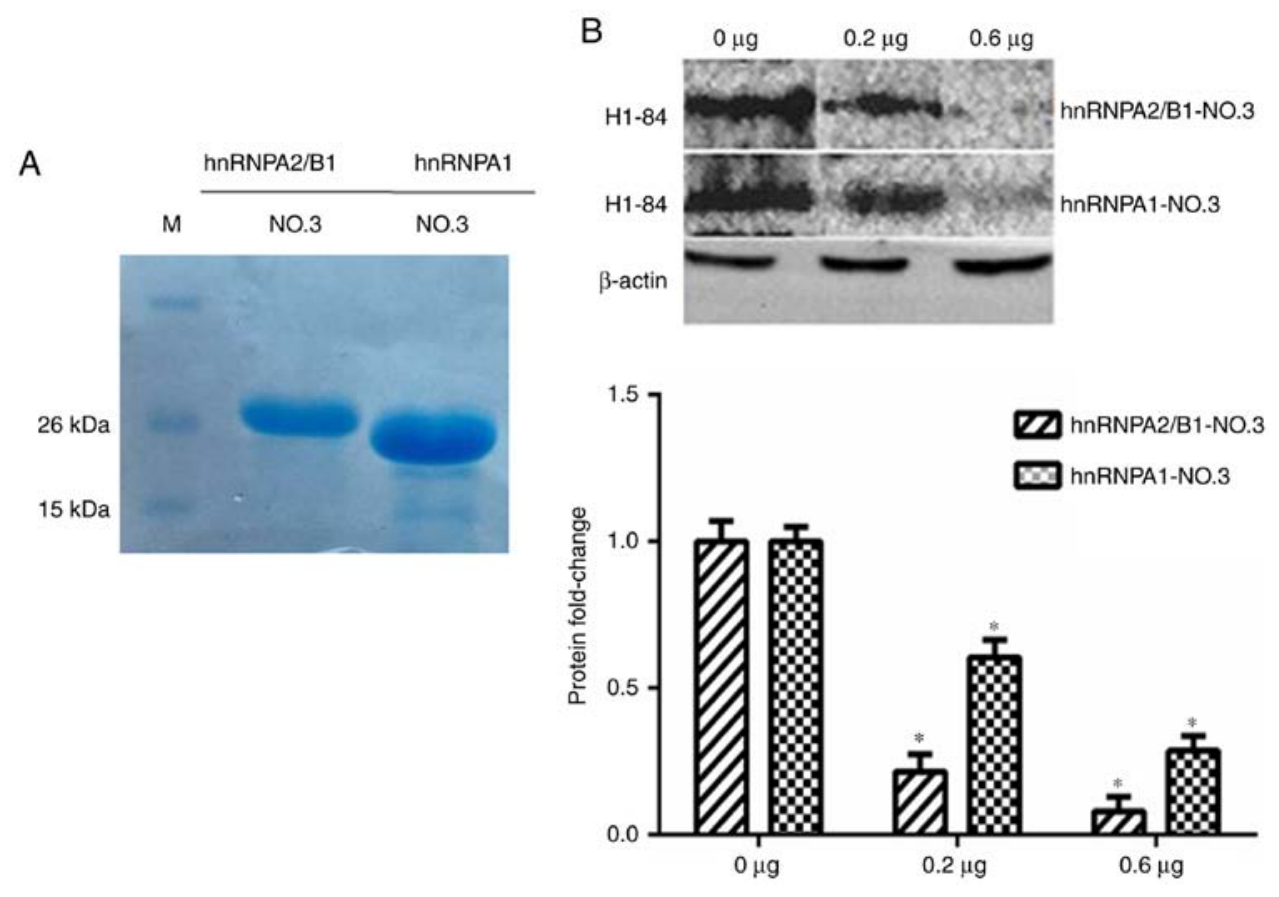

Figure 5. Verification of H1-84mAb combined with brain tissue antigen. (A) Protein purification sample. (B) Separate samples of brain tissue proteins, ensuring the same amount of sample for each well. Pre-incubation of H1-84mAb with 0, 0.2 and $0.6 \mu \mathrm{g}$ hnRNPA2/B1-NO.3 and hnRNPA1-NO.3, respectively. Each incubated sample was different and required separate western blot analysis with brain tissue proteins. The results showed that the NO.3 segments of these proteins were the fine localization of $\mathrm{H} 1-84 \mathrm{mAb}$ on the brain tissue. $\beta$-actin was used as a loading control. ${ }^{*} \mathrm{P}<0.05$ vs. $0 \mu \mathrm{g}$ group.

it is theoretically feasible to mutate the 191/199 epitope of HA to avoid the production of H1-84-like pathogenic antibodies, thereby improving vaccine safety.
In the future, the association between $\mathrm{H} 1-84 \mathrm{mAb}$, Gly-rich domains, neurological diseases and the safety of the vaccine will be investigated further. This will provide experimental 
data for designing a safe influenza vaccine and will be of great significance in preventing influenza virus infection.

\section{Acknowledgements}

Not applicable.

\section{Funding}

The present study was supported by the National Key Research and Development Program of China (grant no. 2016YFD0500700) and the Incubation Fund Program of Shaanxi Provincial People's Hospital (grant no. 2019YXQ-12).

\section{Availability of data and materials}

The datasets used and/or analyzed during the present study are available from the corresponding author upon reasonable request.

\section{Authors' contributions}

$\mathrm{CG}, \mathrm{LS}, \mathrm{SH}$ and $\mathrm{XH}$ designed the study and performed critical revisions; CG, HH, DL, QF, YL and YF performed the laboratory measurements; $\mathrm{CG}, \mathrm{XX}$ and $\mathrm{JH}$ performed the data collection and analysis; and CG drafted the manuscript. All authors read and approved the final manuscript.

\section{Ethics approval and consent to participate}

The animal experiments performed in the present study were approved by the Medical School of Xi'an Jiaotong University Biomedical Ethics Committee and fully meet the requirements of the animal ethics committee.

\section{Patient consent for publication}

Not applicable.

\section{Competing interests}

The authors declare that they have no competing interests.

\section{References}

1. Mahmud SM, Bozat-Emre S, Mostaço-Guidolin LC and Marrie RA: Registry cohort study to determine risk for multiple sclerosis after vaccination for pandemic influenza $\mathrm{A}(\mathrm{H} 1 \mathrm{~N} 1)$ with Arepanrix, Manitoba, Canada. Emerg Infect Dis 24: 1267-1274, 2018.

2. Fukuda M, Yoshida T, Moroki M, Hirayu N, Nabeta M, Nakamura A, Uzu $\mathrm{H}$ and Takasu O: Influenza A with hemorrhagic shock and encephalopathy syndrome in an adult: A case report. Medicine (Baltimore) 98: e15012, 2019.

3. Siegers JY, van de Bildt MWG, Lin Z, Leijten LM, Lavrijssen RAM, Bestebroer T, Spronken MIJ, De Zeeuw CI, Gao Z, Schrauwen EJA, et al: Viral factors important for efficient replication of influenza $A$ viruses in cells of the central nervous system. J Virol 93: e02273-18, 2019.

4. Ninove L, Daniel L, Gallou J, Cougard PA, Charpentier A, Viard L, Roquelaure B, Paquis-Flucklinger V, de Lamballerie X, Zandotti C and Charrel RN: Fatal case of Reye's syndrome associated with $\mathrm{H} 3 \mathrm{~N} 2$ influenza virus infection and salicylate intake in a 12-year-old patient. Clin Microbiol Infect 17: 95-97, 2011.
5. Francis JR, Richmond P, Robins C, Lindsay K, Levy A, Effler PV, Borland $\mathrm{M}$ and Blyth CC: An observational study of febrile seizures: The importance of viral infection and immunization. BMC Pediatr 16: 202, 2016.

6. Cárdenas G, Soto-Hernández JL, Díaz-Alba A, Ugalde Y, Mérida-Puga J, Rosetti M and Sciutto E: Neurological events related to influenza A (H1N1) pdm09. Influenza Other Respir Viruses 8: 339-346, 2014.

7. Tin SS and Wiwanitkit V: Neurological complications after H1N1 influenza vaccination. Arq Neuropsiquiatr 72: 977, 2014.

8. Guo CY, Tang YG, Qi ZL, Liu Y, Zhao XR, Huo XP, Li Y, Feng Q, Zhao PH, Wang X, et al: Development and characterization of a panel of cross-reactive monoclonal antibodies generated using H1N1 influenza virus. Immunobiology 220: 941-946, 2015.

9. Yamamoto M, Cid E and Yamamoto F: Molecular genetic basis of the human Forssman glycolipid antigen negativity. Sci Rep 2: 975, 2012.

10. Wang JJ, Yang GX,Zhang WC,Lu L, Tsuneyama K,Kronenberg M, Véla JL, Lopez-Hoyos M, He XS, Ridgway WM, et al: Escherichia coli infection induces autoimmune cholangitis and anti-mitochondrial antibodies in non-obese diabetic (NOD).B6 (Idd10/Idd18) mice. Clin Exp Immunol 175: 192-201, 2014.

11. Coppieters KT and von Herrath M: Antibody cross-reactivity and the viral aetiology of type 1 diabetes. J Pathol 230: 1-3, 2013.

12. Guo CY, Zhang HX, Zhang JJ, Sun LJ, Li HJ, Liang DY, Feng Q, Li Y, Feng YM, Xie X and Hu J: Localization analysis of heterophilic antigen epitopes of H1N1 influenza virus hemagglutinin. Virol Sin 34: 306-314, 2019.

13. Sun L, Li H, Sun J, Guo C, Feng Y, Li Y, Zhao X, Xie X and Hu J: Antibodies against $\mathrm{H} 1 \mathrm{~N} 1$ influenza virus hemagglutinin cross-react with prohibitin. Biochem Biophys Res Commun 513: 446-451, 2019.

14. Levin MC,Lee SM, Kalume F, Morcos Y, Dohan FC Jr, Hasty KA, Callaway JC, Zunt J, Desiderio D and Stuart JM: Autoimmunity due to molecular mimicry as a cause of neurological disease. Nat Med 8: 509-513, 2002.

15. Yang L, Tu JL and Xiong YS: Influenza-related central nervous system damage. Chin J Neurol 43: 737-738, 2010.

16. Ahmed SS, Volkmuth W, Duca J, Corti L, Pallaoro M, Pezzicoli A, Karle A, Rigat F, Rappuoli R, Narasimhan V, et al: Antibodies to influenza nucleoprotein cross-react with human hypocretin receptor 2. Sci Transl Med 7: 294ra105, 2015.

17. Sarkanen TO, Alakuijala APE, Dauvilliers YA and Partinen MM: Incidence of narcolepsy after H1N1 influenza and vaccinations: Systematic review and meta-analysis. Sleep Med Rev 38: 177-186, 2018.

18. Wekerle H: Vaccination and narcolepsy: Immune link found? Sci Transl Med 7: 1-3, 2015.

19. Krecic AM and Swanson MS: hnRNP complexes: Composition, structure, and function. Curr Opin Cell Biol 11: 363-371, 1999.

20. Levin MC, Lee SM, Gardner LA, Shin Y, Douglas JN and Salapa H: Autoantibodies to heterogeneous nuclear ribonuclear protein A1 (hnRNPA1) cause altered 'ribostasis' and neurodegeneration; the legacy of HAM/TSP as a model of progressive multiple sclerosis. J Neuroimmunol 304: 56-62, 2017.

21. Douglas JN, Gardner LA, Salapa HE, Lalor SJ, Lee S, Segal BM, Sawchenko PE and Levin MC: Antibodies to the RNA-binding protein hnRNP A1 contribute to neurodegeneration in a model of central nervous system autoimmune inflammatory disease. J Neuroinflammation 13: 178, 2016.

22. Sueoka E, Yukitake M, Iwanaga K, Sueoka N, Aihara T and Kuroda Y: Autoantibodies against heterogeneous nuclear ribonucleoprotein B1 in CSF of MS patients. Ann Neurol 56: 778-786, 2004.

23. Lee S, Xu L, Shin Y, Gardner L, Hartzes A, Dohan FC, Raine C, Homayouni R and Levin MC: A potential link between autoimmunity and neurodegeneration in immune-mediated neurological disease. J Neuroimmunol 235: 56-69, 2011.

24. Mishra S, Murphy LC and Murphy LJ: The prohibitins: Emerging roles in diverse functions. J Cell Mol Med 10: 353-363, 2006.

25. Lee SM, Dunnavant FD, Jang H, Zunt J and Levin MC: Autoantibodies that recognize functional domains of hnRNPA1 implicate molecular mimicry in the pathogenesis of neurological disease. Neurosci Lett 401: 188-193, 2006.

26. Gauntt CJ, Arizpe HM, Higdon AL, Wood HJ, Bowers DF, RozekMMandCrawleyR:Molecularmimicry,anti-coxsackievirus B3 neutralizing monoclonal antibodies, and myocarditis. J Immunol 154: 2983-2995, 1995.

This work is licensed under a Creative Commons Attribution-NonCommercial-NoDerivatives 4.0 International (CC BY-NC-ND 4.0) License. 